\title{
Conhecimentos de futuros professores acerca de funções com o uso de tecnologias digitais
}

\author{
Rodrigo Lacerda Carvalho \\ José Aires de Castro Filho
}

\section{Resumo}

A cada experiência, torna-se evidente que o ponto crucial para integrar as tecnologias aos processos pedagógicos é a formação de professores. Para tanto, elegemos elementos teóricos sobre Technological Pedagogical Content Knowledge (TPACK) que aborda como a tecnologia é utilizada no ensino de conceitos específicos, em nosso caso o campo conceitual das estruturas multiplicativas. $\mathrm{O}$ objetivo deste estudo foi analisar $\mathrm{o}$ conhecimento matemático dos futuros professores para o ensino de estruturas multiplicativas a partir da utilização pedagógica das tecnologias digitais. Para tanto, elegemos a pesquisa colaborativa para conduzir os passos metodológicos deste trabalho. Na fase dos resultados nossa intenção foi perceber os momentos que os futuros professores compreenderam a variação de uma função afim. Nesta perspectiva, constatamos que os futuros docentes avançaram do conhecimento comum para o especializado do conteúdo e que o componente tecnológico foi fundamental para ampliar a percepção dos licenciandos em relação à utilização pedagógica da tecnologia.

Palavras-Chave: Função. Formação de professores. Tecnologias digitais. 


\section{Knowledge of future teachers about function of the use of digital technologies}

Rodrigo Lacerda Carvalho

José Aires de Castro Filho

Abstract

With each experience, it becomes evident that the crucial point to integrate the technologies to the pedagogical processes is the formation of teachers. To that end, we have chosen theoretical elements on Technological Pedagogical Content Knowledge (TPACK) that approach how technology is used in teaching specific concepts, in our case the conceptual field of multiplicative structures. The aim of this study was to analyze the mathematical knowledge of future teachers for the teaching of multiplicative structures from the pedagogical use of digital technologies. To do so, we chose the collaborative research to conduct the methodological steps of this work. In the phase of the results our intention was to perceive the moments that the future teachers understood the variation of a related function. In this perspective, we verified that the future teachers have advanced from the common knowledge to the specialized of the content and that the technological component was fundamental to broaden the perception of the graduating in relation to the pedagogical use of the technology.

Keywords: Function. Teacher formation. Digital technologies. 


\section{Introdução}

De acordo com Almeida e Prado (2011), a cada experiência, fortalece a ideia que a formação de professores é relevante para integrar as tecnologias digitais aos processos pedagógicos. Dessa maneira, nossa proposta é que este trabalho seja realizado desde a formação inicial, com os futuros professores vivenciando e refletindo sobre a prática de ensino com tais ferramentas.

As tecnologias digitais de informação e comunicação (TDIC) podem favorecer professores e alunos a superarem obstáculos no processo de ensino e de aprendizagem. Nesta pesquisa, pretendemos utilizar as potencialidades destes recursos integrados ao ensino de Matemática. Borba e Penteado (2010) afirmam que as TDIC podem proporcionar mudanças significativas na prática escolar, criando condições favoráveis para a aquisição e o desenvolvimento de conceitos matemáticos.

A mediação com as TDIC oportunizam diferentes formas de desenvolver o conhecimento pedagógico do conteúdo e da tecnologia. Para este debate, elegemos elementos teóricos sobre Technological Pedagogical Content Knowledge (TPACK) que tem como foco principal pesquisar de que maneira a tecnologia é utilizada no ensino e na aprendizagem de conceitos específicos de uma determinada área do conhecimento (MISHRA; KOEHLER, 2006), em nosso caso a Matemática.

Tendo em vista a abrangência da Matemática, neste artigo, trabalhamos com o campo conceitual das estruturas multiplicativas (VERGNAUD, 2009). O referido campo oportuniza o contato com diferentes situações de multiplicação, divisão e a combinação de tais operações.

Problemas do campo conceitual multiplicativo envolvem conceitos de função linear e não linear, relação escalar direta e inversa, quociente e produto de dimensões, combinação linear e aplicação linear, fração, relação, número racional, dentre outros conceitos. Para a presente pesquisa, teremos como foco o conceito de função.

O objetivo deste estudo foi analisar o conhecimento matemático dos futuros professores para o ensino de estruturas multiplicativas a partir da utilização pedagógica das TDIC. Para tanto, elegemos a pesquisa colaborativa para conduzir os passos metodológicos deste trabalho.

Segundo Teles e Ibiapina (2009), neste método de pesquisa professores e pesquisadores trabalham conjuntamente, em busca de conhecimentos voltados para a melhoria da cultura escolar e para o desenvolvimento profissional dos envolvidos na pesquisa. A seguir debateremos sobre o conhecimento pedagógico da tecnologia e do conteúdo. 


\section{Conhecimento pedagógico da tecnologia e do conteúdo}

Mishra e Koehler (2006) relatam que a construção do TPACK aconteceu na realização de um projeto de experimento que é destinado a compreender o desenvolvimento dos professores para o uso efetivo da tecnologia e ao mesmo tempo colaborar com os atores envolvidos na pesquisa. Nessa perspectiva, pesquisadores e professores trabalham conjuntamente, em busca de conhecimentos voltados para potencializar o uso das TDIC na educação e para o desenvolvimento profissional dos envolvidos na pesquisa.

Segundo Mishra e Koehler (2006) o uso das tecnologias em sala de aula pode variar de simples desenhos em uma lousa interativa ou hipertextos com base na web até sofisticadas simulações multimídia.

Estas possibilidades proporcionam uma série de representações, exemplos e demonstrações que podem levar o discente a compreender os conceitos matemáticos. Este novo contexto tem em primeiro plano a tecnologia de forma que não poderíamos imaginar a alguns anos. Assim, o conhecimento da tecnologia também se torna um aspecto importante do conhecimento geral dos professores.

Na abordagem do TPACK é onde surge a integração do conhecimento pedagógico da tecnologia e do conteúdo. De acordo com Mishra e Koehler (2006), os conhecimentos de conteúdos e de pedagogia, equivocadamente, eram considerados separados e independentes um do outro, a partir de Shulman (1986) e posteriormente Ball, Thames e Phelps (2008) foi que a comunidade científica passou a compreender que não dá para trabalhar com estes conhecimentos de forma separada.

Da mesma forma, hoje em dia, o conhecimento de tecnologia é muitas vezes considerado como separado do conhecimento pedagógico do conteúdo, os autores advertem que não dá para separar estes três tipos de conhecimento.

O entrelaçamento dessas três fontes de conhecimentos é a base da organização do ensino de Matemática com tecnologias e requer uma compreensão de trabalhos pedagógicos que utilizem tecnologias de maneira construtiva para ensinar o conteúdo específico (MISHRA; KOEHLER, 2006). A seguir exibimos a fig 01, que representa de forma compreensível o que significa o TPACK. 


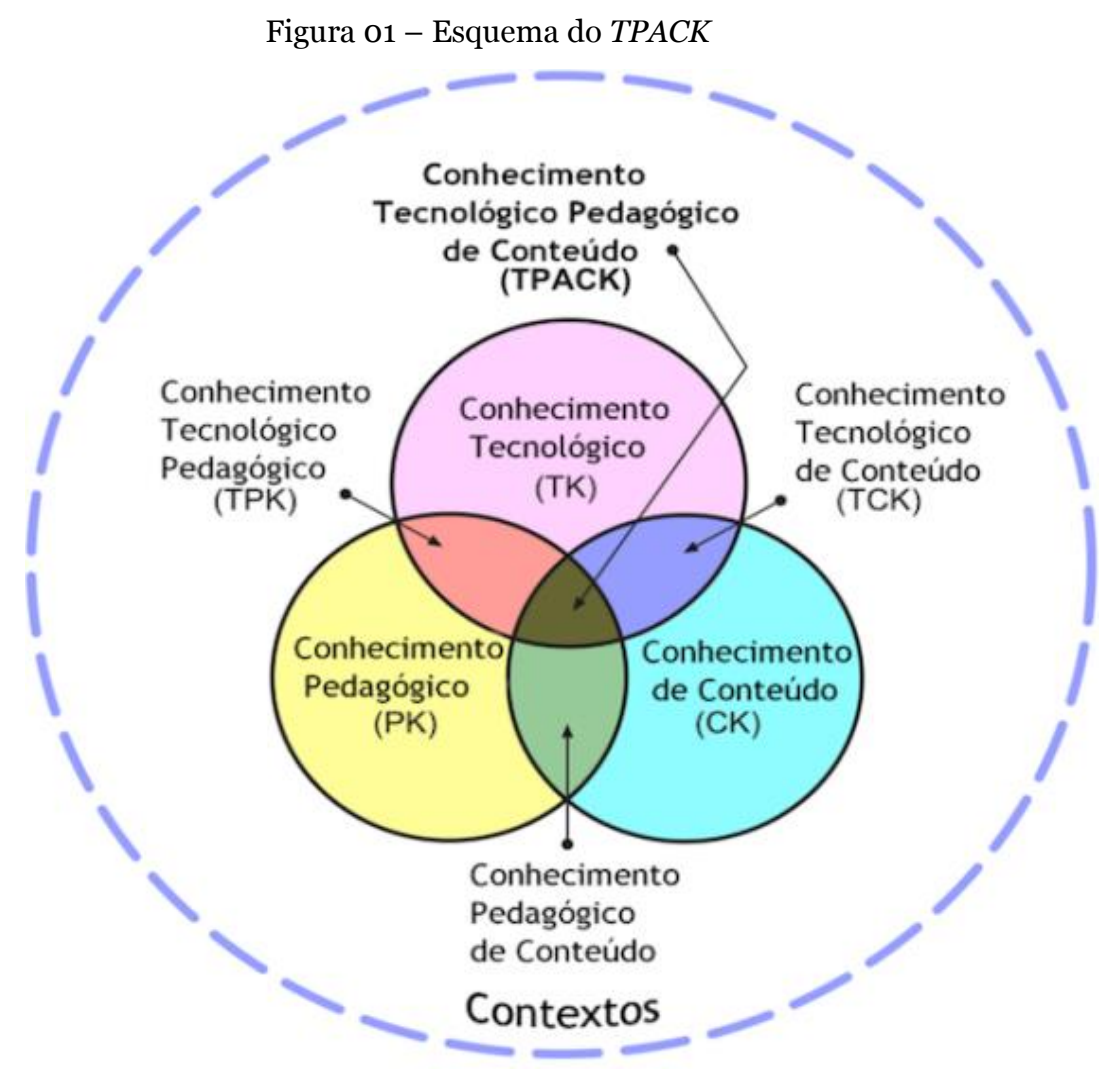

Fonte: https://pt.wikipedia.org/wiki/Tpack

Nessa perspectiva, ressaltamos que saber utilizar a tecnologia não é o mesmo que saber utilizá-la pedagogicamente. Na tentativa de superar alguns destes obstáculos, Mishra e Koehler (2006) propõem o ensino com tecnologias por meio de projetos, pois assim os estudantes tornam-se sujeitos ativos na construção do conhecimento. O ensino e a aprendizagem por meio de projetos incorporam um processo que está presente na construção de artefatos, tais como cursos online e vídeos digitais, que estão localizados na interação entre teoria e prática.

Assim, constatamos que o TPACK além de contribuir para articular uma estratégia entre ensino e tecnologias por meio de projetos, também nos embasa teoricamente para estudar o desenvolvimento dos futuros professores entre o conhecimento matemático para o ensino e a tecnologia educacional.

A partir de diversas pesquisas, Ball, Thames e Phelps (2008) avançaram nas ideias de Shulman (1986) e, para o escopo da Educação Matemática, definiram o que seria o conhecimento matemático para o ensino. Os autores trazem as categorias de conhecimento do conteúdo e de conhecimento pedagógico do conteúdo, subdivididas em conhecimento comum do conteúdo e conhecimento especializado do conteúdo. Em síntese, os autores definem que reconhecer uma resposta errada e se preocupar somente com o resultado final 
de um problema são conhecimentos comuns do conteúdo; enquanto dimensionar a natureza de um erro e se deter ao processo de resolução de um problema são conhecimentos especializados do conteúdo.

Nessa perspectiva, o TPACK nos permite dar sentido às relações que existem quando os futuros professores utilizam a tecnologia para o ensino do conteúdo específico, no caso da presente pesquisa o campo conceitual multiplicativo que será debatido no próximo tópico.

\section{Campo conceitual Multiplicativo}

A Teoria dos Campos Conceituais visa possibilitar uma base consistente às pesquisas sobre atividades cognitivas, especificamente, com referência ao conhecimento matemático. Permite ainda situar e estudar as filiações e as rupturas entre conhecimentos, na perspectiva de seu conteúdo conceitual, isto é, estudar as relações existentes nos conceitos matemáticos (VERGNAUD, 1990).

A partir dos princípios da Teoria dos Campos Conceituais, com foco nas estruturas multiplicativas de Vergnaud; Magina, Merlini e Santos (2016) elaboraram um quadro conceitual adaptando as ideias centrais deste campo. A organização desenvolvida pelos autores está dividida em duas relações, quais sejam, quaternárias e ternárias (VERGNAUD, 2009). A primeira relação é formada por três eixos: proporção simples, múltipla e dupla, e a segunda, por dois eixos: comparação multiplicativa e produto de medidas. Para o presente artigo nosso foco será no eixo de proporção simples.

De acordo com Nunes e Bryant (1997) e Vergnaud (2009), estratégias de resolução presentes nas relações quaternárias, e que as escolas pouco exploram, são os fatores escalar (trabalho com grandezas de mesma natureza) e funcional (trabalho com grandezas distintas). Entre elas há uma taxa de replicação ou de proporcionalidade - a razão - que pode ser identificada pelo fator escalar ou funcional. Nesta pesquisa nossa intencionalidade foi entender como ocorre a passagem do pensamento proporcional ao funcional.

\section{Do pensamento proporcional ao funcional}

A proporção simples trata de uma relação quaternária e pode ser subdivida em duas classes, quais sejam, correspondência um para muitos e correspondência muitos para muitos (MAGINA; MERLINI; SANTOS, 2016). A seguir traremos um problema para debatermos a classe um para muitos, visando compreender a passagem do pensamento proporcional ao funcional.

Problema 1 - A receita do bolo de cenoura de Lis leva 1 copo de leite para 3 cenouras. Ela vai fazer um bolo com 5 copos de leite. Quantas cenouras ela precisará para fazer seu bolo corretamente?

Neste problema, temos o caso de 1 copo de leite que está relacionado com 3 ISSN 2526-2882

$$
* 138 *
$$


cenouras; assim como 5 copos de leite estão relacionados a uma quantidade de cenouras a qual se deseja descobrir, mantendo-se a mesma razão. De acordo com Gitirana et al. (2014), na situação de proporção simples, as razões entre as medidas das grandezas têm que ser as mesmas, assim conhecendo o fator escalar, o estudante pode utilizá-lo na comparação de outra grandeza, conforme Figura 02:

Figura 02 - Proporção Simples - Operador Escalar na resolução do Problema 01

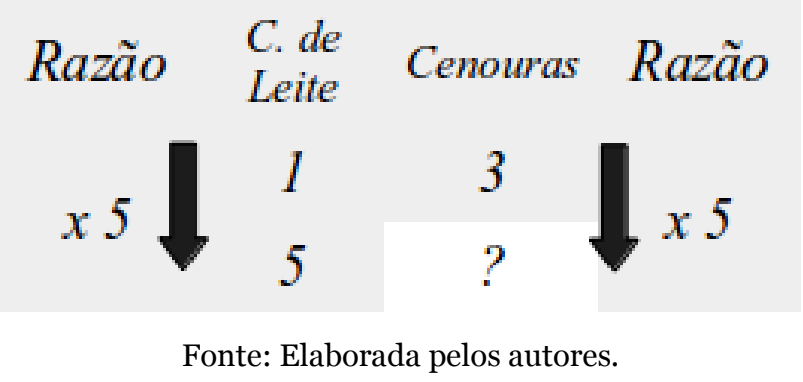

Como descrito acima, o fator escalar pode ser identificado na mesma grandeza ao compreender quantas vezes a unidade aumentou, no caso do copo de leite teve um aumento de cinco vezes, ou seja, o fator escalar é 5, daí ao multiplicarmos o atual número de cenouras por este escalar encontramos a quantidade desejada para o bolo. $\mathrm{O}$ mesmo problema pode ser resolvido pelo fator funcional, que relaciona as duas grandezas, ou seja, leite com cenoura, conforme Figura 03 .

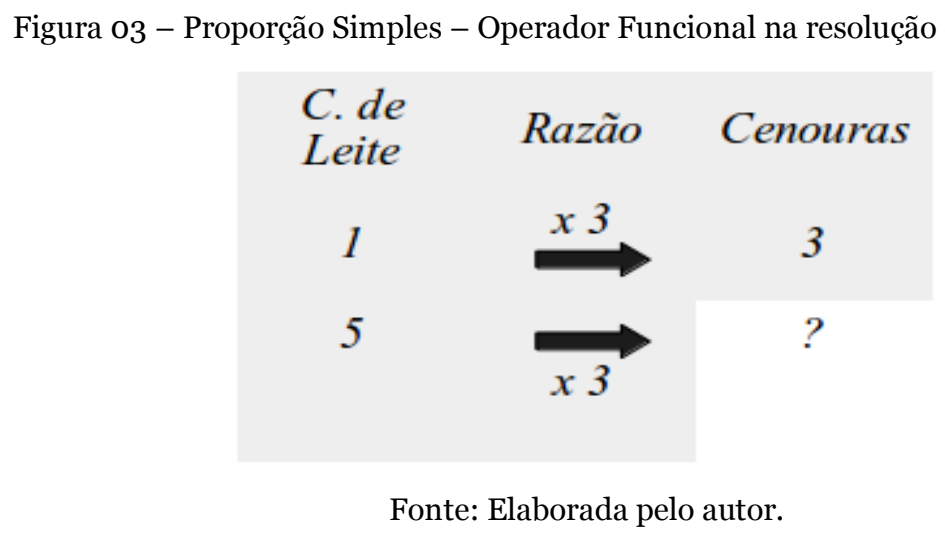

O fator funcional está relacionado na horizontal, ou seja, copos de leite com cenouras, daí como temos 1 copo de leite para 3 cenouras, deduzimos que o operador funcional é três. Vergnaud (1991, p. 210), destaca que "[...] a análise horizontal está em um nível conceitual mais complexo, e essa é uma das razões para a dificuldade dos estudantes na compreensão da noção de função". Este fato justifica a nossa escolha em focar no conceito de

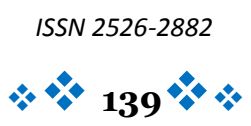


funções.

Podemos constatar que em situações multiplicativas de proporção simples existem relações funcionais e escalares, ou seja, situações de covariação. Smith (2008) ressalta que atividades que demandam um raciocínio funcional são relevantes para formar o conceito de função.

Segundo Teixeira, Magina e Merlini (2016) as relações funcionais podem ser entendidas como o ato de estabelecer relações entre grandezas. Os autores caracterizam tal ato como consequência de um raciocínio funcional. Assim, o raciocínio funcional pode ser definido como a capacidade de estabelecer a relação entre grandezas (TEIXEIRA; MAGINA; MERLINI, 2016). Em uma situação multiplicativa, por exemplo, quando a quantidade de tortas vegetarianas está relacionada à quantidade de legumes, sendo a primeira quantidade uma variável dependente da segunda quantidade. Dessa forma, se 1 torta precisa de 6 legumes, 9 tortas precisam de 54 legumes e $x$ tortas precisam $6 x$ legumes. Esta situação pode ser matematicamente escrita na representação de uma função linear: $f(x)=6 x$, caso particular de uma função afim.

Nessas situações, é possível fazer uma análise entre as grandezas, correspondente ao operador funcional. O raciocínio funcional presente nas situações multiplicativas quaternárias implica no quociente de dimensões, no caso, do exemplo da torta vegetariana, citado anteriormente, temos legumes por torta(s). Assim, ao compreendermos a relação funcional e estabelecermos o operador funcional, temos o coeficiente de uma função linear.

Nesse contexto, faremos um estudo centrado na compreensão dos conceitos essenciais de função afim, baseado nas ideias do campo conceitual multiplicativo. Convém ressaltar que nossa proposta é tentar levar os alunos da licenciatura a compreenderem a relação de dependência entre duas grandezas, uma variando em função da outra, ou seja, a covariação, e também representar tais conceitos de forma algébrica, tabular e gráfica, dentre outros. Nesse sentido, entendemos a covariação como um conceito relevante para compreender o que é uma função afim.

Desta maneira, os futuros professores, ao perceberem a covariação entre duas grandezas, são capazes de coordenar a variação das duas variáveis e descrever como uma grandeza muda em relação à outra (CONFREY; SMITH, 1995). Em uma pesquisa realizada por Monk (1992), o autor destacou que os futuros professores mostram uma tendência a focar mais na construção dos gráficos do que em entender o gráfico de uma função como um meio para definir uma relação de covariação entre duas variáveis.

Saldanha e Thompson (1998) descrevem a covariação como o envolvimento da coordenação de duas quantidades; com a percepção de que o valor de uma quantidade varia de acordo com outro. Assim, compreendemos a covariação como um conceito fundamental 
para o desenvolvimento do pensamento funcional, considerando que problemas desse tipo podem ser representados por meio de uma função afim: $f(x)=a x+b$, com b igual a zero, ou seja, uma função linear.

De acordo com Post, Behr e Lesh (1995), o conhecimento de proporções envolve as situações multiplicativas e de covariação. Uma relação proporcional pode ser representada pela forma algébrica $f(x)=a x$, uma das representações de uma função linear. Os autores abordam que essa representação tem natureza multiplicativa e pode ser representada de maneiras distintas, tais como: tabelas, gráficos, desenhos e diagramas, que constituem formas importantes nas quais podemos representar o raciocínio funcional.

Blanton e Kaput (2004) reforçam que o raciocínio funcional pode ser desenvolvido com a ideia de covariação e de raciocínio proporcional. Essas abordagens podem acontecer com a exploração de diferentes representações, como tabelas e gráficos e o uso de tecnologias para dar dinamicidade a construção dessas representações.

Ferreira (1997) já destacava que os estudantes têm dificuldades no ensino de funções por lidar com múltiplas representações e grande quantidade de conceitos, tais como: covariação, par ordenado, domínio e conjunto imagem. A autora complementa que uma boa alternativa para amenizar esses problemas seria trabalhar funções em ambientes computacionais. Nessa perspectiva, Borba e Penteado (2010, p. 31-32) sublinham que,

[...] usualmente, a ênfase para o ensino de funções se dá via álgebra. Assim, é comum encontrarmos em livros didáticos um grande destaque para a expressão analítica de uma função e quase nada para os aspectos gráficos ou tabulares. Tal destaque muitas vezes está ligado à própria mídia utilizada. Sabemos que é difícil a geração de diversos gráficos num ambiente em que predomina o uso de lápis e papel e, então, faz sentido que não se dê muita ênfase a esse tipo de representação.

Ainda de acordo com Borba e Penteado (2010), no início da década de 90, a abordagem para funções começa a ser bastante questionada, daí começa a ser pesquisado sobre as representações múltiplas para o ensino deste conteúdo. Os autores enfatizam que o importante não é privilegiar apenas um tipo de representação, e sim diferentes representações para uma mesma função: a expressão algébrica, o gráfico e a tabela.

É relevante ressaltar que, além de trabalhar com cada uma das representações de forma isolada, devemos abordar as coordenações entre elas, como um novo caminho para o conhecimento de funções, ou seja, uma epistemologia das representações múltiplas, que variam de forma conjunta. Dessa maneira, entender funções passa a significar saber coordenar representações e compreender a covariação que existem entre elas. Essa nova abordagem ganha força com ambientes computacionais que geram gráficos vinculados à tabelas e expressões algébricas, dentro desta perspectiva estaremos trabalhando ao encontro ISSN 2526-2882

$$
* 141 *
$$


dos elementos teórico do TPACK. Desta maneira, procuraremos evidenciar na pesquisa aqui relatada um possível caminho para a melhoria do ensino de funções.

No próximo tópico, iremos expor as opções metodológicas deste trabalho, o que se constitui como aspecto essencial para garantir a viabilização de todo o desenvolvimento da investigação, bem como a obtenção de resultados confiáveis.

\section{Metodologia}

Segundo Anadón (2007), a pesquisa colaborativa é composta por três etapas. A primeira é a co-situação, momento da incorporação dos participantes na investigação. A segunda etapa denominada co-operação, diz respeito ao processo de reflexão acerca das questões de pesquisa. A terceira etapa é a co-produção, que é o momento de construção coletiva, ou não, do trabalho. A autora aponta ainda que essas etapas representam os espaços criados para a efetivação de pesquisa e formação, propostas pela pesquisa colaborativa. Fiorentini e Lorenzato (2009) salientam que o prefixo co significa ação conjunta.

Segundo Loiola (2004), a co-situação é a etapa da pesquisa colaborativa que responde às preocupações do contexto dos futuros professores e do contexto da pesquisa. Nessa fase, o papel principal do pesquisador consiste em procurar a mediação entre esses dois contextos. Esse momento deve ser construído para que os envolvidos passem a se sentir motivados para colaborar e inserir-se no grupo. É nessa etapa que se dão as negociações e a inserção em um projeto que visa contribuir para a produção e compartilhamento de saberes docentes (TELES; IBIABINA, 2009).

Antes de efetivamente iniciarmos a co-situação, fizemos a definição do município Brejo Santo (CE) - e do lócus da pesquisa, qual seja, a Universidade Federal do Cariri (UFCA), mais especificamente no Instituto de Formação de Educadores (IFE) que é instalado na cidade supracitada. A escolha desta cidade deveu-se ao fato de ser local que recebeu as instalações do IFE, reunindo cursos de formação pedagógica, ou seja, cursos de licenciatura em diversas áreas do conhecimento. $\mathrm{O}$ curso pesquisado foi a Licenciatura Interdisciplinar em Ciências Naturais e Matemática, que permite uma formação geral interdisciplinar e específica nas áreas de Biologia, Física, Matemática e Química. Já a definição pela UFCA enquanto local da pesquisa deveu-se ao desejo de ampliar o conhecimento sobre os estudantes e contribuir de maneiras diversas com a instituição em que atuamos como professor efetivo da área de Ensino de Matemática. No IFE, selecionamos quatro participantes para a pesquisa que atendessem aos seguintes critérios:

a) ser bolsista em um dos quatro pilares que sustentam esta Universidade: Ensino, Pesquisa, Extensão e Cultura;

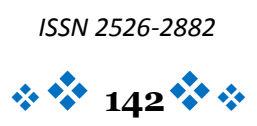


b) ter disponibilidade para participar da pesquisa; e

c) permitir e participar da análise e publicação dos dados colhidos no momento em que aconteceu a formação.

A opção por selecionar somente os bolsistas, deveu-se ao fato destes estudantes terem efetivamente tempo para participar da pesquisa. Além disso, não consideramos um processo de exclusão, pois todos os alunos do Instituto que podem ter bolsas já foram contemplados, importa registrar que em alguns editais tivemos sobra de bolsas. A fim de resguardar os participantes da pesquisa criamos códigos para os nomes dos futuros professores, quais sejam, D2, I3, J4 e N5.

A etapa da co-situação, aconteceu no mês de abril de 2015. Foram realizados 2 encontros nos quais discutimos a proposta da pesquisa, caracterizamos o perfil e os conhecimentos prévios dos futuros professores e refletimos sobre a prática docente. Assim, percebemos o interesse dos licenciandos pela participação efetiva em uma pesquisa dessa natureza.

A co-operação, fase escolhida para a coleta dos dados deste artigo, foi o momento em que pesquisador e licenciandos refletiram sobre o ensino do campo conceitual das estruturas multiplicativas e sobre a utilização pedagógica das tecnologias digitais. Essa fase foi realizada nos meses de abril a dezembro de 2015, em um total de 16 encontros. Convém ressaltar que selecionamos dois encontros para serem discutidos no presente artigo. A seguir temos o detalhamento dos referidos momentos no quadro 1.

Quadro 01- Cronograma dos encontros da fase de co-operação

\begin{tabular}{|c|c|l|}
\hline $3^{0}$ & $2 / 10 / 15$ & $\begin{array}{l}\text { - Debate sobre o objeto de aprendizagem Grande Prêmio Funcional (GP Funcional) } \\
\text { A partir do referido OA, estudamos o gráfico de uma função afim e os seus coeficientes, } \\
\text { debatemos quando uma função é crescente ou decrescente a partir da análise do gráfico } \\
\text { e do coeficiente angular. } \\
\text { - Situações problemas sobre funções no GP Funcional. }\end{array}$ \\
\hline $4^{0}$ & $4 / 11 / 15$ & $\begin{array}{l}\text { - Discussão sobre o recurso digital Variação da Função Afim da Universidade Federal } \\
\text { Fluminense (UFF) } \\
\text { Com este recurso estudamos o comportamento variacional da função afim fazendo uso } \\
\text { de recursos gráficos, numéricos e algébricos. Também caracterizamos uma função afim } \\
\text { por meio de seu comportamento variacional; e utilizamos processos de modelagem } \\
\text { matemática para resolver problemas do cotidiano, tendo como referência o } \\
\text { comportamento variacional da função afim. Além disso, estimulamos os futuros } \\
\text { professores a criarem conjecturas e fazerem generalizações. } \\
\text { - Situações problemas sobre funções no recurso Variação da Função Afim (UFF). }\end{array}$ \\
\hline
\end{tabular}

Fonte: Elaborado pelos autores

O objeto de aprendizagem (OA) Grande Prêmio Funcional foi produzido pelo Grupo 
de Pesquisa e Produção de Ambientes Interativos e Objetos de Aprendizagem - PROATIVA ${ }^{8}$ que tem por objetivo desenvolver objetos de aprendizagem com a intenção de dividir os conteúdos disciplinares em pequenos trechos que podem ser utilizados em vários ambientes de aprendizagem, bem como realizar pesquisas sobre a utilização desses objetos na escola, como forma de melhorar a aprendizagem dos discentes.

O objeto de aprendizagem variação da função afim foi desenvolvido pela Universidade Federal Fluminense (UFF9) e apresenta um conjunto de atividades interativas que permite estudar o comportamento variacional da função afim.

Nas formações tínhamos como foco discussões colaborativas. Durante estes momentos buscamos compreender algumas questões, quais sejam:

i) Como as concepções dos futuros professores se alteraram ao longo da formação?

ii) Relação de dependência e variância das grandezas de uma função: O que é uma função? Como podemos coordenar a covariação de uma função?

iii) Representação gráfica e tabular de uma função: Os futuros professores têm dificuldades em encontrar padrões em uma tabela? Eles entendem gráficos de funções? Evidenciam a relação do gráfico de uma função linear com o operador funcional?

Buscamos também constatar o avanço dos futuros professores em relação à compreensão de conceitos matemáticos a partir da utilização pedagógica das tecnologias digitais. A seguir, trataremos dos resultados da pesquisa.

\section{Análise dos dados}

Nesta fase dos resultados da pesquisa nossa intenção foi perceber os momentos que os futuros professores compreenderam a variação de uma função afim. Primeiramente expomos uma discussão por meio da utilização do GP Funcional e posteriormente com o recurso digital Variação da Função Afim.

Solicitamos aos futuros docentes que entrassem no GP Funcional na opção "conhecendo os coeficientes", para manipularem livremente os coeficientes $a$ e $b$ e observarem e discutirem como o gráfico se comportava. Após a manipulação, iniciamos alguns debates para entender as percepções dos licenciandos, nossa estratégia foi estabelecer condições para as mediações necessárias entre os futuros professores e o conhecimento especializado do conteúdo (BALL; THAMES; PHELPS, 2008) a partir da utilização pedagógica das tecnologias digitais. A seguir temos a geração de gráficos no GP Funcional realizada pelos futuros professores.

$8 \mathrm{http://www.proativa.vdl.ufc.br/} \mathrm{(Texto} \mathrm{baseado} \mathrm{na} \mathrm{descrição} \mathrm{dos} \mathrm{criadores} \mathrm{do} \mathrm{projeto)}$

9 http://www.uff.br/cdme/afim/afim-html/guia-do-professor.html (Texto baseado na descrição dos criadores do projeto)

$$
\text { ISSN 2526-2882 }
$$


Figura 04 - Gráficos no GP Funcional, $a>0$

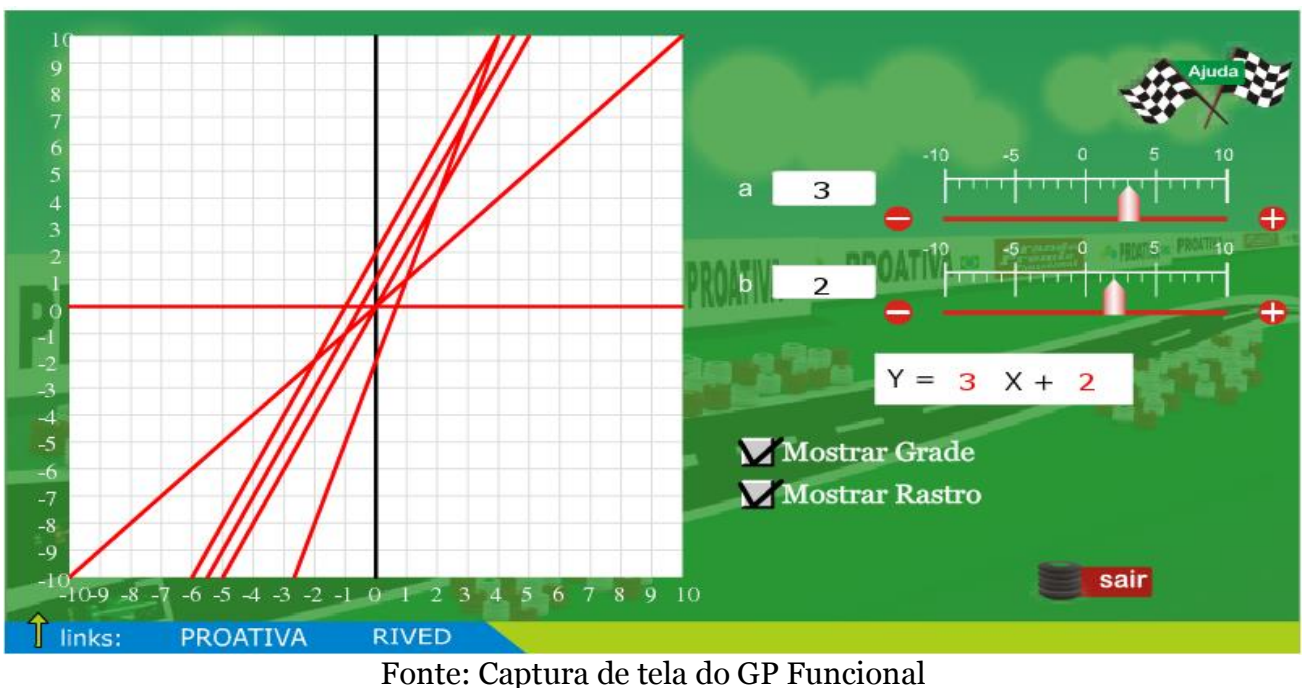

Figura 05 - Gráficos no GP Funcional, $a<0$

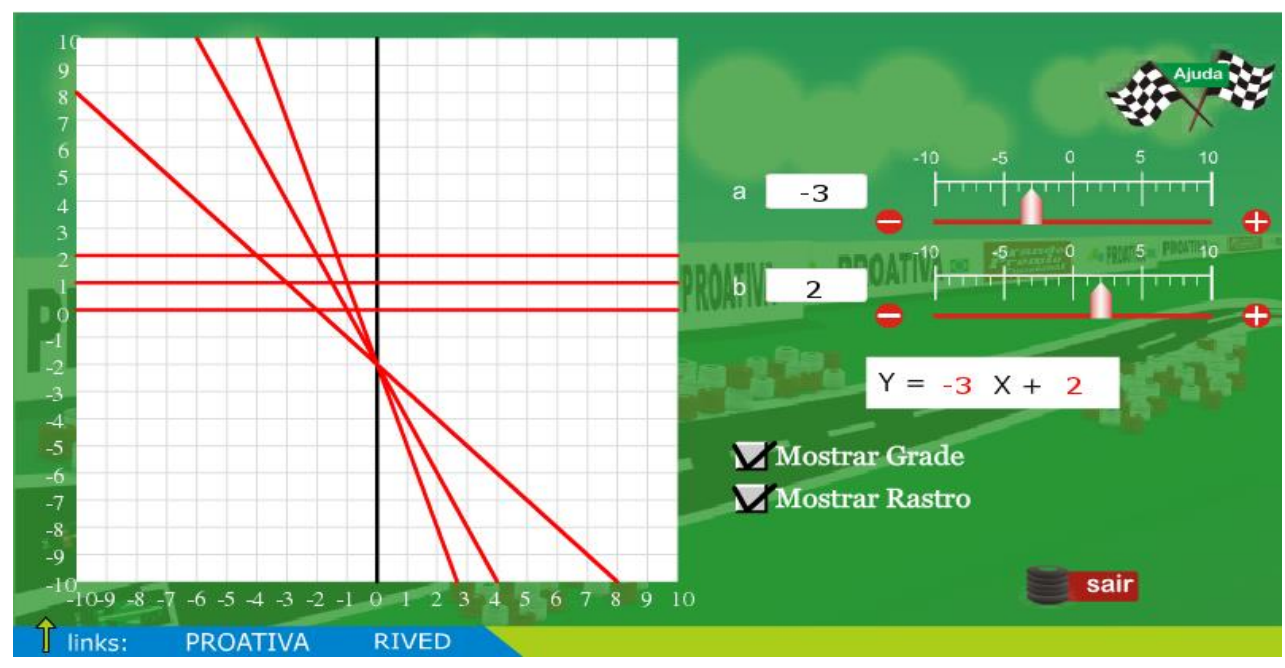

Fonte: Captura de tela do GP Funcional

Nos gráficos acima, os futuros professores escolheram as funções $f(x)=3 x+2$ e $f(x)$ $=-3 x+2$ na forma algébrica. Colocaram a opção mostrar rastro da reta que é um comando que mostra o caminho percorrido pela reta no gráfico. Por meio desta possibilidade do GP Funcional, os futuros professores visualizaram todo o caminho percorrido pela reta desde a origem, fato que ficaria impossível apenas com a manipulação do papel e do lápis. A seguir, vejamos o que os futuros docentes comentaram sobre este momento:

“Pesquisador - Quando alteramos os valores das funções o que acontece com a posição das retas no gráfico?

N5 - As retas mudam de inclinação.

D2 - Esta ideia de mostrar o rastro da reta é muito legal! A partir daí a gente pode perceber o caminho da reta desde a origem até a função escolhida neste momento.

I3 - O interessante D2 é que a gente vai visualizando o movimento do coeficiente angular e ISSN 2526-2882 
linear da função afim e depois podemos constatar o que cada um significa na função.

Pesquisador - Vocês poderiam me dizer o que cada um significa na função?

N5 - O coeficiente angular significa o valor da inclinação de uma reta em relação ao eixo das abscissas. Já o linear o ponto da reta que toca o eixo das ordenadas.

D2 - Realmente agora compreendo como uma função vai variando.

I3 - Tem toda uma ligação entre a representação algébrica e gráfica. Tive noção disso agora com o uso dos recursos digitais, antes pensava que não tinha nenhuma relação.

D2 - A tecnologia utilizada de maneira pedagógica para ensinar um conteúdo faz toda a diferença."

Ao compartilhar e articular ideias, os futuros docentes puderam ensinar uns aos outros e assim construírem e compreenderem conceitos de como variam os coeficientes de uma função afim. Neste caso, o OA fomentou o levantamento, a troca, a experimentação (BORBA; PENTEADO, 2010) e partilha de ideias pelos aprendizes. A tecnologia contribuiu com os licenciandos para perceberem a variação dos coeficientes $a$ e $b$ da função afim. Os futuros professores constataram que o coeficiente $a$ tem relação com a inclinação da reta e o $b$ têm relação com a ordenada do ponto $(\mathrm{o} ; \mathrm{b})$ e que as representações gráfica e algébrica têm uma relação e são formas distintas de representar uma mesma função. Em geral, observamos que os efeitos de translação e rotação mantêm um padrão de variação em qualquer função de variável real.

Os futuros professores além de conseguirem estabelecer uma relação entre os coeficientes de uma função afim conseguiram representar a função seguindo esse mesmo padrão, seja de forma algébrica ou gráfica. Passaram, portanto, a coordenar a variação de uma função (CONFREY; SMITH, 1995).

Os licenciandos relataram que agora compreendem efetivamente o comportamento variacional de uma função afim e que com a utilização de recursos tecnológicos foi possível compreender melhor estes conceitos. Portanto, evidenciamos que os futuros docentes conseguiram compreender um conceito por meio da utilização pedagógica das tecnologias, ou seja, tomaram consciência da relevância do conhecimento pedagógico da tecnologia e do conteúdo e que estes três aspectos não devem ser trabalhados de forma separadas (MISHRA; KOEHLER, 2006).

A seguir abordamos a exploração do recurso digital Variação da Função Afim da UFF para continuarmos o debate de como a referida variação acontece em uma função afim. Iniciamos com uma manipulação colaborativa para que os futuros professores explorassem o recurso como ferramenta para a compreensão da variação da função afim. Posteriormente, os licenciandos resolveram e debateram uma atividade proposta no presente recurso.

Com este recurso, abordamos o comportamento variacional da função afim fazendo uso de diversas representações, quais sejam, recursos gráficos, tabulares, numéricos e algébricos. Também caracterizamos uma função afim por meio de seu comportamento 
variacional; e resolvemos problemas do cotidiano, tendo como referência o comportamento variacional da função afim.

Em nosso primeiro debate com este recurso digital, começamos relembrando a definição de uma função afim. Definimos como função afim quando existem números reais e tais que o gráfico de uma função afim é uma reta onde os números reais assumem um papel especial no traço dessa reta. O debate dos participantes da pesquisa sobre esta questão pode ser verificado abaixo:

\footnotetext{
"Pesquisador $-A$ expressão $f(x)=a x+b$ o que significa?

D2 - A lei de formação!

N5 - A lei de formação, generaliza a função.

Pesquisador - E o que significa o $x$ ?

D2 - x é o que varia de forma independente, você atribui valores a ele e encontra os pares ordenados para fazer o gráfico!

Pesquisador - Quem é o domínio e a imagem da função?

I3 - O domínio é onde eu posso atribuir valores a vontade e a imagem são os valores que eu encontro a partir de uma lei de formação.

Futuros Professores - $O$ domínio é o x e a imagem é o $f(x)$. E o a e b são os coeficientes angular e linear. No linear a reta toca no eixo y."
}

A partir desta discussão, que relembrava sobre o conceito da função afim em suas representações algébrica e gráfica, evidenciamos que os futuros professores conseguiram chegar a um conhecimento especializado do conteúdo (BALL; THAMES; PHELPS, 2008). Os futuros docentes muitas vezes esbarravam no conhecimento comum do conteúdo, mas agora podemos constatar esta evolução. Possivelmente podemos atribuir como uma das contribuições das tecnologias digitais abordadas no processo de formação colaborativa. Assim, os licenciandos passaram do conhecimento comum para o conhecimento especializado do conteúdo, aspecto fundamental para o exercício da prática docente.

A seguir temos a atividade que foi explorada com a utilização do recurso digital variação da função afim. Segue o enunciado do problema: Uma locadora de automóveis cobra "p" reais por quilômetro rodado mais uma taxa fixa de "q" reais. Os valores de p e de q variam de acordo com o modelo de automóvel escolhido. Como se trata de uma empresa informatizada, ela dispõe de um aplicativo que simula para o cliente o valor a ser pago pelo aluguel. Para o aluguel de um carro popular a empresa cobra $\mathrm{R} \$ 40,00$ de taxa fixa e $\mathrm{R} \$ 0,50$ para cada quilômetro rodado. Sugerimos escolher o valor de $10 \mathrm{~km}$ para $\Delta s$. Isto significa que o aplicativo irá calcular o valor a ser pago pelo cliente a cada $10 \mathrm{~km}$.

Desta maneira, os futuros professores adotaram os seguintes passos:
a) deslocaram os botões de acordo com os valores indicados;
b) clicaram no botão iniciar para executar o aplicativo;
c) observaram as variações que foram registradas; $\mathrm{e}$
d) realizaram um debate a partir de suas observações. ISSN 2526-2882 
A seguir temos, a imagem do que aconteceu com a manipulação do referido recurso digital e em seguida o debate realizado pelos futuros docentes.

Figura 06 - Variação da Função Afim

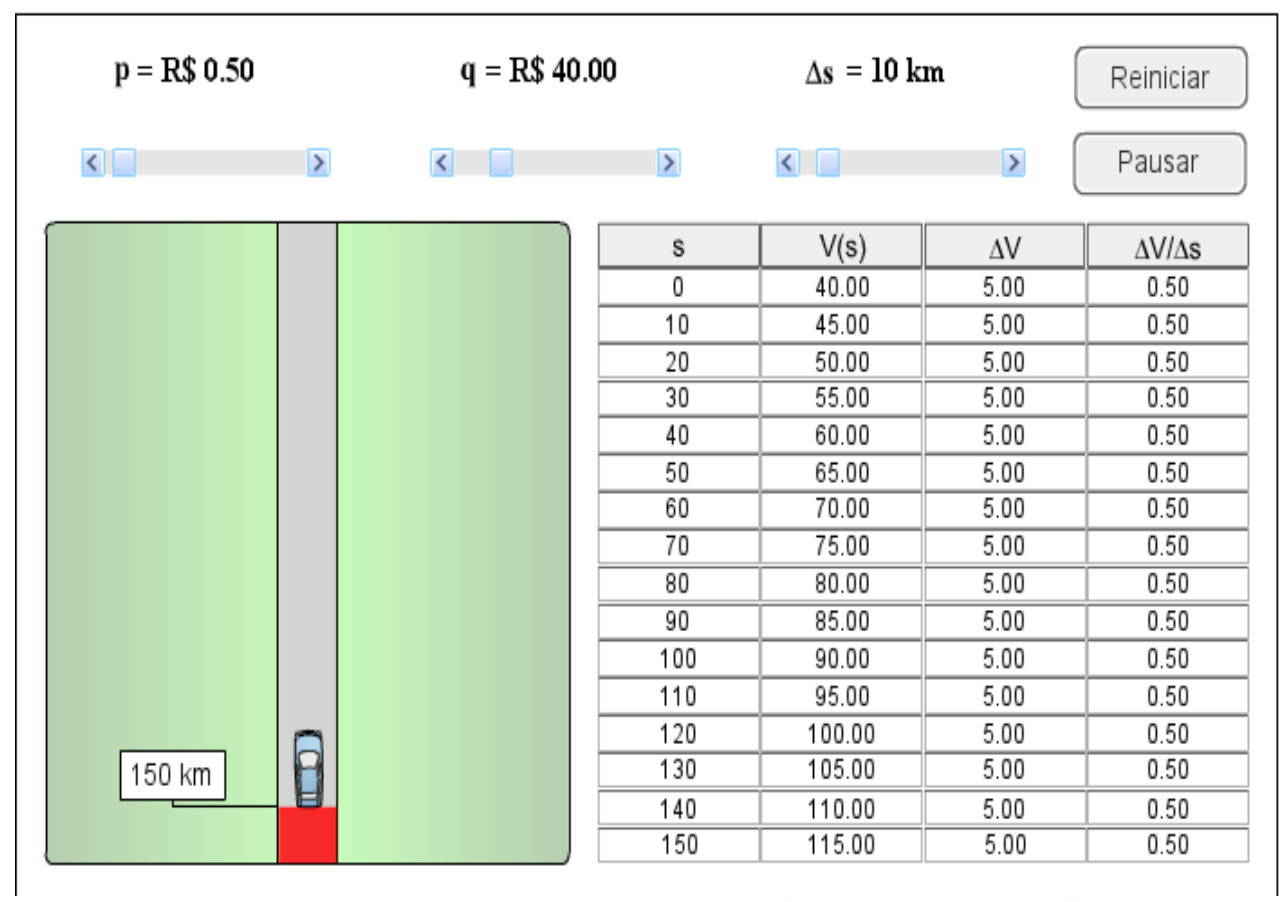

Fonte: Captura de tela do Variação da Função Afim

"I3 - Os Km variam com os reais.

D2 - Percebi que os km influenciam no preço a ser pago.

N5 - Quanto mais quilômetros a gente andar, mais caro vai ser.

J4 - Além da variação a gente percebe uma relação de dependência.

I3 - Exato! O valor que a gente paga depende da distância percorrida

J4 - Duas questões fundamentais para o entendimento do conceito de funções.

Pesquisador - Quais?

Futuros Professores - A variação e a dependência

Pesquisador - Quem seria a lei de formação desta função?

D2 $-\mathrm{f}(\mathrm{x})=0.5 \mathrm{x}+40$

N5 - Legal que a gente trabalhou com as representações algébrica e tabular.

Pesquisador - Vocês saberiam me dizer o que significa o AV?

J4 - A variação do valor

I3 - Significa que a cada $10 \mathrm{~km}$ aumenta 5 reais.

Pesquisador - E o AV/AS?

D2 - A divisão da variação do valor pela variação do espaço.

N5 - Olha aí as estruturas multiplicativas. A multiplicação e a divisão sempre interligadas.”

Ressaltamos que os futuros professores, por meio da visualização e da experimentação, constataram duas importantes características do conceito de função, quais sejam, a variância e a dependência. Estas características são fundamentais para a compreensão da covariação, ou seja, a coordenação entre grandezas. Outro aspecto retratado pelos licenciandos foi sobre as representações algébrica e tabular. Coordenar múltiplas representações também é relevante para o entendimento do conceito de função (BORBA; ISSN 2526-2882

$$
* 148 *
$$




\section{PENTEADO, 2010).}

Segundo Confrey e Smith (1995), as representações tabulares são relevantes porque necessitam que sejam gerados um padrão de sequências e isto envolve a covariação. Assim, os futuros professores ao percebem a covariação entre duas grandezas foram capazes de descrever como uma grandeza muda em relação à outra.

Blanton e Kaput (2005) analisaram que representações tabulares e animações icônicas podem ser utilizadas para expressar generalizações, ou seja, utilizar um conjunto de representações que compõe um conceito. De acordo com Vergnaud (1990, p. 76) "[...] a verificação do significado de representações simbólicas depende não só da habilidade que o sujeito tenha para representar as entidades e as relações entre elas, mas principalmente de elementos conceituais que devem ser levados em conta.". Desta maneira, compreendemos que a tabela e as animações icônicas podem ser usadas para introduzir abordagem mais explícita da covariação em funções.

Nesta perspectiva, constatamos que os futuros docentes avançaram do conhecimento comum para o especializado do conteúdo (BALL; THAMES; PHELPS, 2008) e que o componente tecnológico trabalhado na formação foi fundamental para este avanço e para ampliar a percepção dos licenciandos em relação à utilização pedagógica da tecnologia.

\section{Conclusões}

O avanço constatado na percepção dos futuros professores participantes da pesquisa no decorrer da investigação revela que a formação é um espaço relevante para o debate sobre o campo conceitual das estruturas multiplicativas e também sobre a utilização das tecnologias no ensino de funções.

Ao longo da presente pesquisa, percebemos que os futuros docentes adquiriram um conhecimento pedagógico das tecnologias. Podemos considerar este um dos grandes ganhos da nossa formação colaborativa.

Assim, por meio da pesquisa colaborativa, fizemos uma parceria entre os futuros professores e o pesquisador para a produção de conhecimentos de funções com tecnologias digitais. A contribuição dos futuros professores como participantes do processo oportunizou que diferentes conhecimentos sobre o ensino e a aprendizagem de funções fossem desenvolvidos.

Os futuros professores realizaram movimentos de construção e reconstrução em busca do conhecimento das estruturas multiplicativas, especificamente o conhecimento de funções. Nos momentos de discussão, os participantes expuseram seus pontos de vistas que foram argumentados com os demais membros do grupo. Esse movimento de construção coletiva foi fundamental para este processo de formação colaborativa na busca do

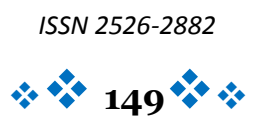


conhecimento matemático para o ensino.

Neste contexto, os futuros docentes manipularam livremente os recursos digitais e perceberam o comportamento da reta no gráfico e depois formalizaram seus próprios conceitos. Desta maneira, utilizando as tecnologias digitais, os futuros professores chegaram à formalização dos conceitos de função afim e a conclusão de que a curva do seu gráfico sempre é uma reta.

Na categoria que emergiu sobre a variação da função afim, os futuros professores caracterizaram uma função afim por meio de seu comportamento variacional. Por meio da manipulação de recursos digitais, os licenciandos constataram as características de variância e a dependência da função afim. Ambas características foram fundamentais para a compreensão da covariação e para a passagem do conhecimento comum para o especializado do conteúdo. Nesta perspectiva, as tecnologias foram fundamentais para a construção do conhecimento sobre o ensino de estruturas multiplicativas, com foco nos conceitos de função.

\section{Referências}

ALMEIDA, M. E. B.; PRADO, M. E. B. B. Indicadores para a formação de educadores para a integração do laptop na escola. In: ALMEIDA, M. E. B.; PRADO, M. E. B. B. (Org.). O computador portátil na escola: mudanças e desafios nos processos de ensino e aprendizagem. São Paulo: Avercamp, 2011.

ANADÓN, M. E. Novas dinâmicas na pesquisa educativa e formação continuada dos docentes: os modelos participativos. In: COLÓQUIO NACIONAL EPISTEMOLOGIA DAS CIÊNCIAS DA EDUCAÇÃO, 9., 2007, Natal. Anais... Natal: EDUFN, 2007. p. $1-14$.

BALL, D. L.; THAMES, M. H.; PHELPS, G. Content knowledge for teaching: what makes it special?. Journal of Teacher Education, New York, v. 59, n. 5, p. 389 - 407, nov./dez. 2008. Disponível em: $<$ https://www.math.ksu.edu/ bennett/onlinehw/qcenter/ballmkt.pdf>. Acesso em: 3 ago. 2015.

BLANTON, M. L.; KAPUT, J. J. Elementary grades students' capacity for functional thinking. In: CONFERENCE OF THE INTERNATIONAL GROUP FOR THE PSICHOLOGY OF MATHEMATICS EDUCATION, 28., 2004, Oslo. Proceedings... Oslo: PME, 2004. v. $2, \quad$ p. 135-142. Disponível em: <http://emis.math.tifr.res.in/proceedings/PME28/RR/RRo33_Blanton.pdf>. Acesso em: 13 out. 2016.

Characterizing a classroom practice that promotes algebraic reasoning. Journal for Research in Mathematics Education, v. 5, n. 36, p. 412-446, ISSN 2526-2882 
2005. Disponível em: <http://www.jstor.org/stable/30034944>.. Acesso em 13 out. 2016.

BORBA, M. C.; PENTEADO, M. G. Informática e Educação Matemática. 4. ed. Belo Horizonte: Autêntica, 2010.

CONFREY, J.; SMITH, E. Splitting, covariation, and their role in the development of exponential functions. Journal for Research in Mathematics Education, v. 26, n. 1, p. 66-86, 1995. Disponível em: <http://www.jstor.org/stable/749228>. Acesso em 7 jun. 2016.

FERREIRA, V. G. G. Aproveitando o Potencial Dinâmico do Computador no Ensino de Função Matemática. In: 13. Encontro de Pesquisa Educacional do Nordeste: Educação Matemática, 1997, Natal. John A. Fossa Org. - Natal: EDUFRN, 1998.

FIORENTINI, D.; LORENZATO, S. Investigação em educação matemática: percursos teóricos e metodológicos. 3. ed. Campinas: Autores Associados, 2009.

GITIRANA, V.; CAMPOS, T. M. M.; MAGINA, S.; SPINILlO, A. Repensando multiplicação e divisão: contribuições da Teoria dos Campos Conceituais. São Paulo: PROEM, 2014.

LOIOLA, L. J. S. L. Contribuições da pesquisa colaborativa e do saber prático contextualizado para uma proposta de formação continuada de professores de Educação Infantil. Fortaleza, 2004. 327 f. Tese (Doutorado em Educação) - Programa de Pós-Graduação em Educação, Universidade Federal do Ceará, Fortaleza, 2004.

MAGINA, S.; MERLINI, V. L.; SANTOS, A. A estrutura multiplicativa à luz da Teoria dos Campos Conceituais: uma visão com foco na aprendizagem. In: CASTRO FILHO, J. A. et al. Matemática, cultura e tecnologia: perspectivas internacionais. Curitiba: CRV, 2016. p. 65-82.

MISHRA, P.; KOEHLER, M. J. Technological pedagogical content knowledge: a framework for teacher knowledge. Teachers College Record, v. 108, n.6, p. 1017-1054, 2006.

MONK, S. Students' understanding of a function given by a physical model. In: HAREL, G.; DUBINSKY, E. The concept of function: aspects of epistemology and Pedagogy. Washington, DC: Mathematical Association of America, 1992. p. 175-193.

NUNES, T.; BRYANT, P. Crianças fazendo Matemática. Porto Alegre: Artes Médicas, 1997.

POST, T. R.; BEHR, M. J.; LESH, R. A proporcionalidade e o desenvolvimento de noções préálgebra. In: COXFORD, A. F.; SHULTE, A. P. (Org.). As idéias da álgebra. São Paulo: Atual, 1995. p. 89-103.

SALDANHA, L. A.; THOMPSON, P. W. Re-thinking covariation from a quantitative ISSN 2526-2882 
perspective: Simultaneous continuous variation. In: BERENSON, S. et al. Proceedings of the Twentieth Annual Meeting of the North American Chapter of the International Group for the Psychology of Mathematics Education. Raleigh: PME, 1998. v. 1, p. 298-303.

SHULMAN, L. S. Those who understand: knowledge growth in the teaching. Educational Researcher, Washington, US, v. 15, n. 2, p. 4-14, 1986.

SMITH, E. Representational thinking as a framework for introducing functions in the elementary curriculum. In: KAPUT, J. J.; CARRAHER, D. W.; BLANTON, M. L. Algebra in the early grades. New York, NY: Lawrence Erlbaum Associates, 2008. p. 133-163.

TEIXEIRA, C.; MAGINA, S.; MERLINI, V. Introdução do raciocínio funcional para estudantes do $5^{\circ}$ ano do ensino fundamental. In: XII Encontro Nacional de Educação Matemática. ISSN 2178-034X. São Paulo - SP, 13 a 16 de julho de 2016.

TELES, F. P.; IBIAPINA, I. M. L. M. A pesquisa colaborativa como proposta inovadora de investigação educacional. Diversa, ano 2, n. 3, p. 1-10, jan./jun. 2009. Disponível em: $\quad$ <http://leg.ufpi.br/subsiteFiles/parnaiba/arquivos/files/rded3ano2_art_05_a\%2opesquisa_colaborativa.pdf>. Acesso em 20 nov. 2104.

VERGNAUD, G. La théorie de champs conceptuels. Recherches en Didactique de Mathématiques, Grenoble, v. 10, n. 2.3, p. 133-170, 1990.

Recherches em didactique des mathématiques. Vol 10.23. 133-170. Grenoble, La Pensée Sauvage éditions 1991.

. A criança, a Matemática e a realidade: problemas do ensino da Matemática na escola elementar. Curitiba: UFPR, 2009.

\section{Biografia Resumida}

José Aires de Castro Filho - Bacharel em Engenharia Civil pela UFC; Mestre em Psicologia Cognitiva pela UFPE; Ph.D em Educação Matemática pela University Of Texas At Austin. professor Titular da Universidade Federal do Ceará, docente do programa de Pós-Graduação em Educação Brasileira da UFC; Líder do Grupo de Pesquisa e Produção em Ambientes Interativos e Objetos de Aprendizagem (PROATIVA). ISSN 2526-2882 
Link do lattes: http://lattes.cnpq.br/1001172700194924

e-mail: aires@virtual.ufc.br

Rodrigo Lacerda Carvalho - Licenciado em Matemática pela UECE; Mestre em Educação pela UECE; Doutor em Educação Brasileira pela UFC; Professor Adjunto da Universidade Federal do Cariri (UFCA); Líder do Grupo de Pesquisa EDUCMÍDIA.

Link do lattes:http://lattes.cnpq.br/2352144605333782.

e-mail: rodrigo.lacerda@ufca.edu.br 